\title{
Analysis of Condenser Performance Desalination of Solar Energy of The Natural Vacuum System at The Time of Low Radiation Intensity
}

\author{
H. Ambarital, E.Y. Setyawan ${ }^{2}$ \\ ${ }^{1}$ Department of Mechanical Engineering, University of North Sumatra, Medan, Indonesia \\ ${ }^{2}$ Department of Mechanical Engineering, National Technology Institute, Malag, Indonesia \\ Email:himsar@usu.ac.id
}

\begin{abstract}
Natural desalination device solar vacuum system has a main component of evaporator, condenser, and solar collector. The production of clean water from this appliance is strongly influenced by the performance of the condenser.On this research, condenser performance is performed when the intensity of solar radiation is low. The measurement data for 2 days when the sky is not bright is used to perform the condenser performance analysis. The result of analysis on the first day was found that the working energy of condensorsirippada was $141 \mathrm{~J} /$ day, while if without $29 \mathrm{~J} /$ day fins. So that the effectiveness of fins of $112 \mathrm{~J} /$ day. While on the second day found heat transfer using $122 \mathrm{~J} /$ day fins without fins 25 $\mathrm{J} /$ day to obtain fin effectiveness of $97 \mathrm{~J} /$ day. This is very influential on clean water production. The condensate rate on the 1st day is highest at $0.00018 \mathrm{~kg} / \mathrm{min}$, with an average of one day experiment $0.0001 \mathrm{~kg} / \mathrm{min}$, yielding fresh water of 0.8 Liter. On the 2 nd day the highest condensate rate is $0.00019 \mathrm{~kg} / \mathrm{min}$ with an average of condensate rate for one day $0.00011 \mathrm{~kg} / \mathrm{min}$, yielding fresh water of 0.81 Liter.
\end{abstract}

Keywords Condenser, Solar Energy, Desalination, Vacuum System Paper type Research paper

\section{INTRODUCTION}

One of the most important human needs is clean water. The scarcity of clean water is increasing now, due to the increasing population growth and the increasing of industrial estates, regardless of the environmental impacts of the production already made, so that many water sources are polluted by these industrial activities. This development is expected to increase and make natural sources of clean water will be reduced very drastically. According to the United Nations, by 2025 there will be about nearly 1800 million people in the world will be under water scarcity [1]. So the technology needed to answer the issue is to use desalination technology. Desalination process is a process that converts sea water into fresh water. The desalination process requires a sizable energy source. At this time many sources of energy derived from fossils or fuel oil used to run the desalination process. Moving the desalination process using renewable energy is a green technology that one can use solar energy to produce freshwater from the ocean water [2].

The desalination technology using solar energy can reduce the use of fossil fuels, thereby reducing emissions of greenhouse gases today. The sun is a promising source of renewable energy that can meet the energy needs of mankind in the future. At present there are a number of desalination units operated by renewable energy. By all these renewable energy desalination units, approximately $57 \%$ of them use solar energy as their energy source [3]. In the desalination process solar energy can be used directly or indirectly to drive desalination process. There have been many studies reported about some desalination methods of solar energy. One of the highlights is the desalination process of the natural vacuum system. On the solar desalination system the evaporation process can take place atrelatively low temperatures when performed in a vacuum environment. Vacuum conditions can be made naturally by utilizing the gravity of sea water at an altitude of about 10 meters. Several studies of natural desalination solar vacuum systems have been found in the literature. Al-Kharabsheh and Goswani [4,5] conducted preliminary experimental and theoretical research on the desalination of natural vacuum systems using the heat from low-quality solar energy. Effects of some operating parameters have been tested.Tests with weather conditions in Gainesville, Florida show that a system with collector area and evaporator surface area of $1 \mathrm{~m} 2$ each produce $6.5 \mathrm{~kg}$ of fresh water per day.Gude et al [6] reported a study on the solar desalination of a natural vacuum system using a solar collector with $18 \mathrm{~m} 2$ collector area and the system combined with thermal energy storage. This system can produce $100 \mathrm{~L} /$ day of clean water. Not only to produce clean water, a vacuum solar desalination system can also be combined with a solar-powered air cooling system. This system can produce fresh water at $4.5 \mathrm{kh} /$ hour and $3.25 \mathrm{~kW}$ cooling capacity [7]. In another study [8], research has been reported on a natural vacuum flash desalination system operated in a one-stage and two-stage mode and supported with a $1 \mathrm{~m} 2 \mathrm{solar}$ collector. This system can produce $5.54 \mathrm{~kg}$ and $8.66 \mathrm{~kg}$ of clean water when operated with single stage and double stage 
system. The performance ratios are 0.748 and 1.35 , respectively. In another study, it was reported about natural vacuum solar desalination consisting of evaporators that received direct solar radiation and condensers in a more shady place. To provide better water production, the blower is used to transfer the vapor from the evaporator to the condenser [9]. The authors have also reported research related to natural vacuum solar desalination. At the time of the laboratory a solar desalination device was created and tested [10]. Field testing in Medan by modifying the evaporator has also been reported [11]. Recent research [12] reported that the rate of production of a natural vacuum solar desalination device depends on the intensity of the sun and the temperature of the environment that cools the condenser.

The literature review made above suggests that a natural vacuum solar desalination study is being noticed by researchers. The resulting freshwater production is still low. One component that gives effect to this production rate is the condenser. In this study will be analyzed condenser performance when solar radiation intensity is low enough. The purpose of this study was to obtain the performance of condensers operating at low radiation intensity. The expected result of this study is to provide important information in terms of developing a natural vacuum desalination solar system.

\section{METHOD}

This study is an experimental study conducted on a solar desalination device a natural vacuum system that functions to convert sea water into fresh water. The tool to be tested has been designed to build. The components of the tool are evaporator with stainless steel 304 material with cylindrical shape with top cone, height and thickness of each evaporator is $80 \mathrm{~cm}, 20 \mathrm{~cm}, 5 \mathrm{~mm}$ and $2 \mathrm{~mm}$ thick and conical part has bottom diameter $40 \mathrm{~cm}$; top diameter $1.2 \mathrm{~mm}$ and $3 \mathrm{~mm}$ thick. Condenser is made in the form of horizontal tube with diameter and length $150 \mathrm{~mm}$ and $500 \mathrm{~mm}$. This tool is made of stainless steel material with thickness of $2.54 \mathrm{~mm}$. The condenser cooling medium used is air around the test site. The cooling process of the condenser is assisted by 20 fins mounted to the condenser section. To provide better heat transfer, the fins are made of aluminum with a diameter of $254 \mathrm{~mm}$ and thickness and $0.6 \mathrm{~mm}$. The distance between the fins is $40 \mathrm{~mm}$. Evaporators and condensers are placed at a location $10.33 \mathrm{~m}$ above the ground. The reason is to provide a natural vacuum in the desalination system. Systematically the seawater inside the evaporator is heated by a heating coil that carries heat with the help of a water fluid as a transfer medium from a solar collector. Since the pressure in the evaporator is below the atmosphere and is near absolute, the water will be volatile. The resulting vapor will flow to the lower pressure condenser seen in Figure 1. The water that reaches the condenser wall will condense and form the condensate to be collected into fresh water as the product.

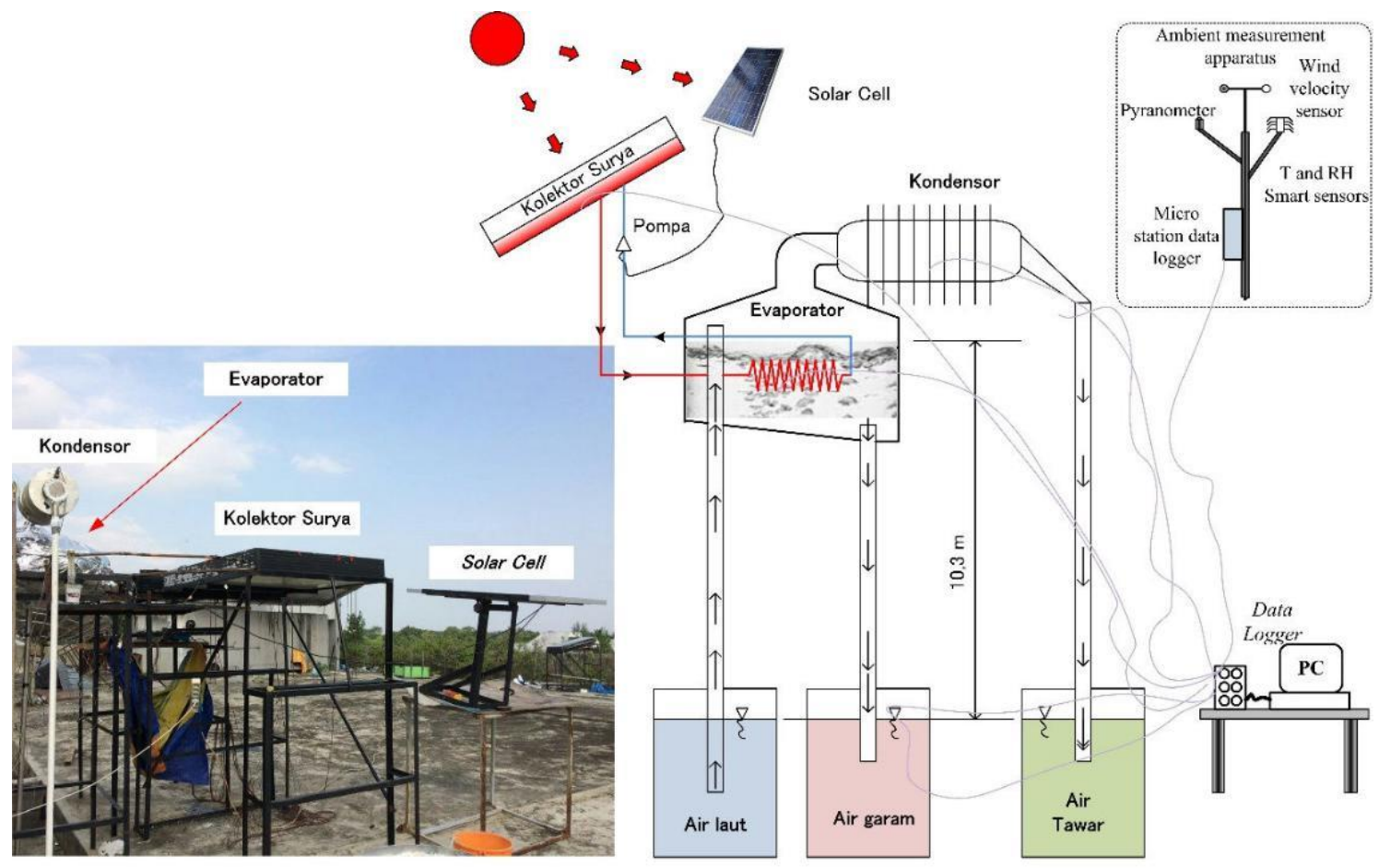

(a) Foto

(b) Skema Sistem

Figure 1. Photo of Experiment Tool and Desalination Scheme 
From the schematic in FIG. 1 in the condenser, the vapor will be condensed because of the temperature difference (Lower Temperature). Where the condenser is cooled by natural convection from the surrounding air to avoid heat from the evaporator transferred to the condenser, added flange filled with rubber sheets that have low conductivity. This system makes the evaporator at higher temperatures, while maintaining the condenser at room temperature. To provide better heat transfer to the condenser, a series of circular fins were added to the outer surface. The condensed steam will be collected as a product of the system and fed into freshwater reservoirs. The concentration of salt in seawater will increase. Salt water will flow into the salt shelter through a heat exchanger. Since the salt water from the evaporator still has high temperatures, the heat will be exchanged for seawater into the evaporator. This process is a preheating stage for seawater before entering the evaporator. The resulting freshwater flow in the condenser water and the brine from the evaporator will make the evaporator pressure lower. Low pressure on the evaporator will make the flow of sea water into the evaporator through sea water pipes. This fact shows that all currents in the system are driven naturally. Short desalination is the separation of sea water with fresh water with the difference of boiling point between sea water with fresh water which has a lower boiling point will evaporate first. In the desalination process occurs the evaporation process in this study energy is extracted from the solar collector used to evaporate seawater in the evaporator and is steeped in the condensation step that is the change of vapor back into liquid which is added condenser tube with fins to reduce the thermal energy flowing from the evaporator. The steam moves toward the condenser, which is the cooling process, so that the vapor that enters the condenser will re-melt. The main objective is to demonstrate the performance of the condenser tube in the desalination process by adding the fins on the outside of the tube as shown in figure 2 .

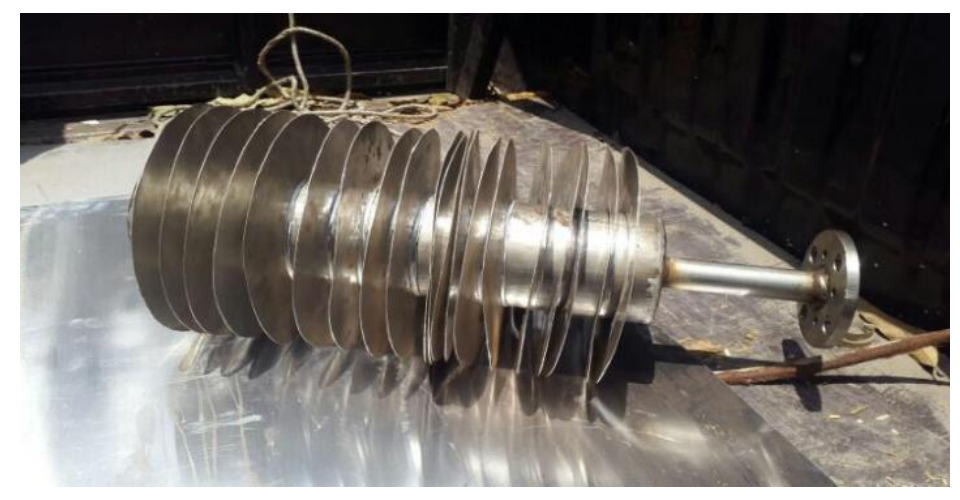

Figure 2. Condenser

\section{DISCUSSION}

The condenser in this system is in the form of an inclined tube and along the tube there is a fin that serves to accelerate the condensation process in the condenser. The faster the condensation process, the faster the fresh water produced. Obtained experimental results in July 2017 conducted in the city of Medan, which is included in the province of North Sumatra. Intake of experimental data conducted for 2 days done at 8.00 WIB until 16.00 WIB is local time to do experiments. Figure 3 shows the results of radiation measurements of solar energy during testing. In the graph theoretical radiation calculations are also shown. From the graph of theoretical radiation and radiation measurements it can be seen that the magnitude of radiation energy coming during the test takes place in the range of $8 \mathrm{MJ} / \mathrm{m} 2$. As is known that the intensity of radiation is an important factor, because the desalination experiments process is highly dependent on solar energy. 

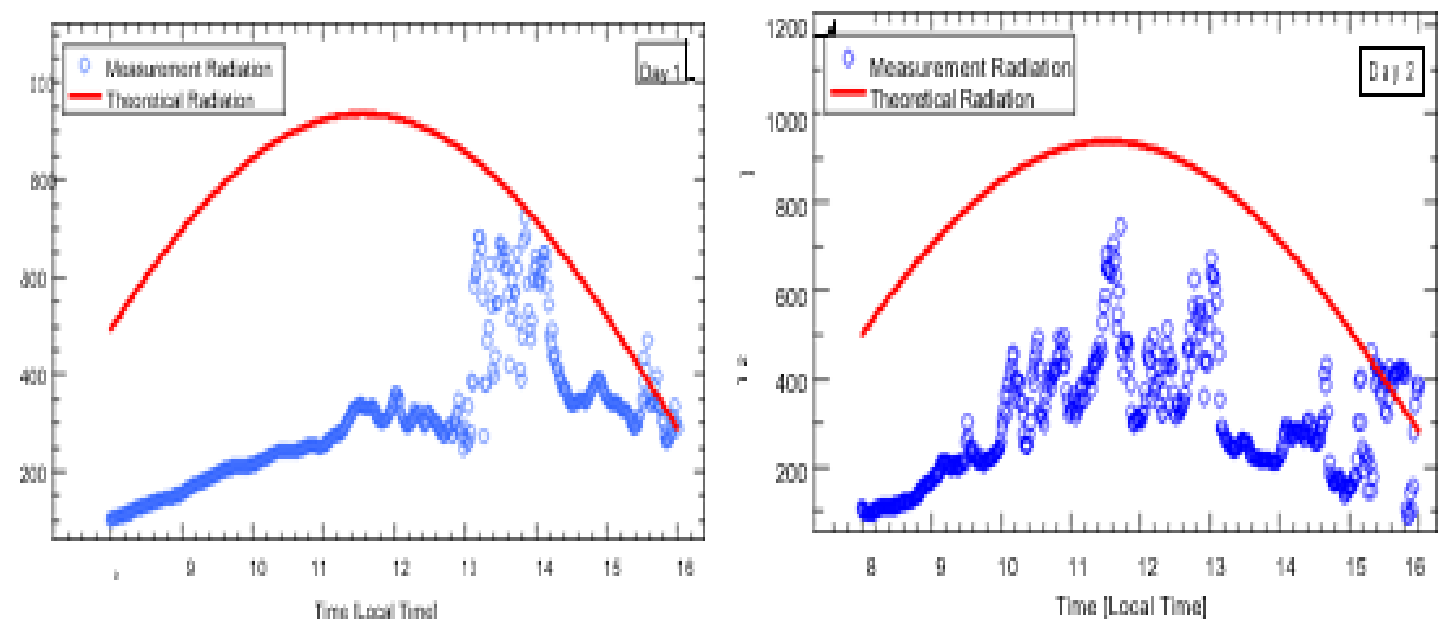

Figure 3. Theoretical Radiation and Radiation Measurements

The image analysis shows overall, the measurement radiation curve performed by HOBO is below the theoretical calculation radiation curve line. This is due to cloudy and cloudy measurement conditions. The radiation calculation curve represents the ideal of the clear sky shown in Figure 3. Where the measured solar radiation is indicated by the blue circle sign and the bright sky radiation shown by the red line. During the experiment, the measurement was well below the radiation of the clear sky due to cloudy and overcast sky conditions. As it was on the 1 st day of the experiment, the weather conditions were overcast so that the total energy obtained $8.798 .634 \mathrm{~J} / \mathrm{m} 2$ and on the second day obtained the total energy $8.746 .800 \mathrm{~J} / \mathrm{m} 2$ better than the 1st day although the difference is not too far included in the sky cloudy and overcast. $2^{\text {nd }}$ day shows better solar radiation. because the solar radiation is close enough to theoretical radiation of the sky, so that more energy is gained.
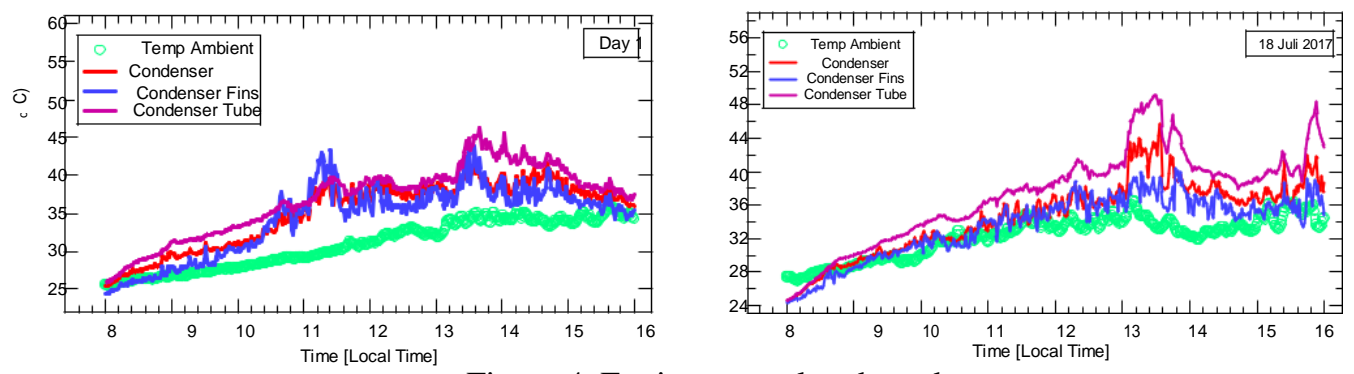

Figure 4. Environmental and condenser temperatures

To know the characteristics of the condenser, used data taken from the thermocouple, with the help of a multi channel data logger (Agilent 34972A) is used to record wih 1 minute of temperature. The measured temperature will be displayed as a graph in Figure 4. As illustrated, the temperature of the condenser shows the same tendency as the solar irradiation. In general, during the day the temperature increases with time and after the day, it decreases with time. Temperatures can go down abruptly when the sun's irradiation falls. The number clearly indicates that the highest temperature is captured on the condenser pipe portion. This is because the condenser pipe is still a single system with evaporator whose temperature is still high because it gets additional energy from solar collector. While the condenser's fins lower temperatures than condensers because the condenser fin wall is directly adjacent to the outside air around the lower temperature which has an average air velocity of $0.8 \mathrm{~m} / \mathrm{s}$ on the first day while on the second day has a speed of $0.4 \mathrm{~m} / \mathrm{s}$. Condenser temperature greatly affects condensation rate in the condenser, because it is an important factor in a desalination system. The temperature at thermocouple refers to average temperature on day 1 ie $360 \mathrm{C}$ while the highest temperature reaches $46.30 \mathrm{C}$ at $13: 29$ is due to the intensity of the coming sun quite high at noon. While on the 2 nd day has an average temperature of $37.30 \mathrm{C}$ is higher than on day 1 it is possible that the intensity of the sun is blocked by clouds or the weather is overcast. Can be proven with the highest temperature obtained for 49.3 occurred at 13:29 hours. 

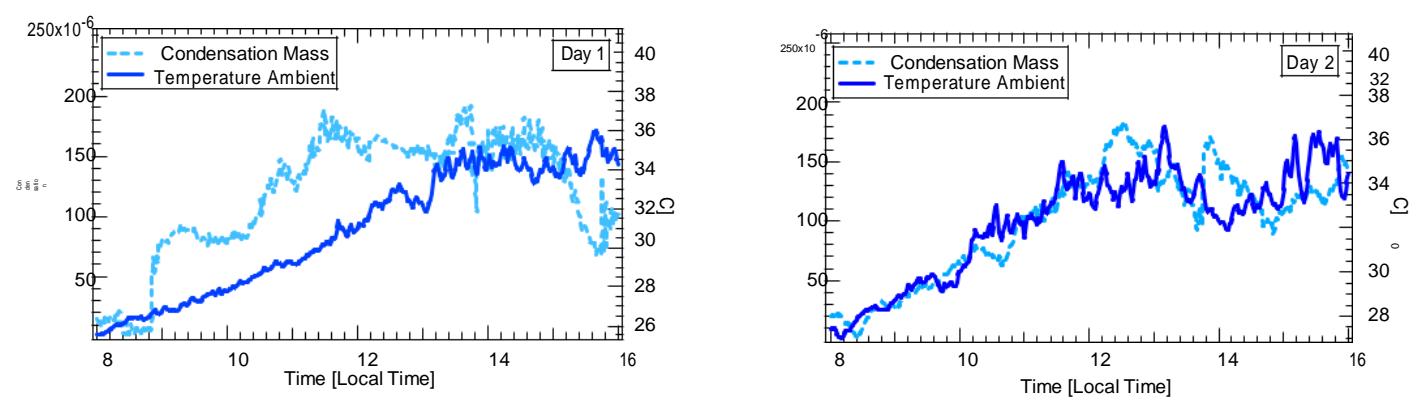

Figure 5. Water mass of condensation

In this experiment also presented graph of condensate mass rate seen in figure 5 . At the graph the highest condensate rate is $0.00018 \mathrm{Kg} / \mathrm{min}$ with the average of one day experiment $0.0001 \mathrm{Kg} / \mathrm{min}$. On the 2nd day the highest condensate rate is $0.00019 \mathrm{Kg} / \mathrm{min}$ with the average condensate rate for one day $0.00011 \mathrm{Kg} / \mathrm{min}$. with fresh water yield on the 1 st day of 0.8 Liter on the 2 nd day yielded 0.81 Liter. All depends on the intensity of the coming sun. To know condensate rate in condenser used equation as below:

$$
h_{\text {inner surface }}=0.555\left[\frac{g \mathrm{p}_{l}\left(\mathrm{p}_{l}-\mathrm{p}_{v}\right) k_{l}^{3}}{\mu_{l}\left(T_{\text {sat }}-T_{s}\right)}\left(h_{f g}+\frac{3}{8} C_{p l}\left(T_{\text {sat }}-T_{s}\right)\right)\right]^{1 / 4}
$$

Which $\mathrm{h}$ is the convection heat transfer coefficient $\mathrm{W} / \mathrm{m}^{2} \mathrm{~K}, \mathrm{~g}$ is the speed of gravity, $\mathrm{m} / \mathrm{s}^{2}, \mathrm{p}$ is the density of the water, $\mathrm{kg} / \mathrm{m}^{3}, \mathrm{pv}$ is the density of the vapor, $\mathrm{kg} / \mathrm{m} 3, \mathrm{k}$ is the conductivity $\mathrm{w} / \mathrm{mK}$, $\mathrm{u}$ is the water viscosity, $\mathrm{kg} / \mathrm{m}$ $\mathrm{s}$, Tsat is the temperature of water saturation, ${ }^{\circ} \mathrm{C}$, Ts is the surface temperature of the pipe, ${ }^{\circ} \mathrm{C}$, hfg is the evaporative fixture, $\mathrm{J} / \mathrm{kg}$, and $\mathrm{Cpl}$ is the specific water heat, $\mathrm{J} / \mathrm{kg}^{\circ} \mathrm{C}$. The graph above shows a high temperature difference between the temperature of the vapor and the environment. Because the vapor gets heat energy from the solar collector through the aid of fluid to bring energy into the evaporator, to increase the evaporator rate in the evaporator. So that the temperature in the vapor can be quite high because it borders the evaporator whose temperature is high enough. So inside the condenser is added fins to expand the heat transfer process. To find the catalyzed condition, the following equation is used:

$$
m L_{c}=L_{c}^{3 / 2} \sqrt{h /\left(K A_{p}\right)}
$$

Which $\mathrm{h}$ is the heat transfer coefficient on the air side $\left(65 \mathrm{~W} / \mathrm{m}^{2}\right), \mathrm{k}$ is the conductivity of the aluminum fins $(202 \mathrm{~W} / \mathrm{mK}), \mathrm{t}$ is the thickness of the fin $(\mathrm{m}), \mathrm{r} 1=$ the radius of the pipe, $\mathrm{r} 2$ is the fin radius . While based on the design of the data used on this fin is rsirip = 5 inches, the fin thickness is $0.7 \mathrm{~mm}$, nilair 1 is 2 inches, the $\mathrm{r} 2$ value is $0.127 \mathrm{~m}$ and the value of $\mathrm{N}=20$.

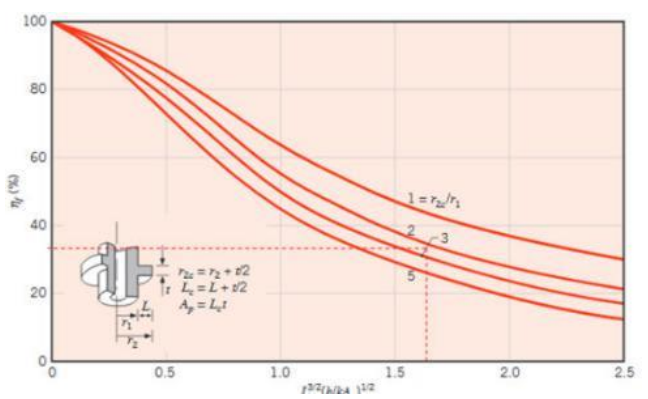

Figure 6. The effectiveness of the fins [13]

By using the fin effectivity chart, the effectiveness of fin is $\alpha=0.35 \%$. Where heat transfer energy using fin $\mathrm{qt}=$ $141 \mathrm{~J}$ while without fins qwo $=29 \mathrm{~J}$ on the 1 st day while the 2 nd day heat transfer energy using fin $\mathrm{qt}=122 \mathrm{~J}$ without using fin qwo $=25 \mathrm{~J}$. To know the ability of fin used equation.

$$
\Delta q=q_{t} q \text { wo }
$$

where qt energi heat transfer using fin, J, while qwo do not use fin, J, so that obtained energy of fin ability at day 1 equal to $112 \mathrm{~J}$ for day 2 its energy equal to $97 \mathrm{~J}$. Figure 6 . The effectiveness of the flippers in the desalination system condenser is known to be $0.35 \%$. It is the ability of the fins to lower the temperature of the condenser by expanding the heat transfer area. So obtained the energy of the fin, on the heat transfer condenser by using a fin J / day without using $29 \mathrm{~J} /$ day fins to obtain the effectiveness of fins of $112 \mathrm{~J} /$ day on day-1. While on the second day found heat transfer using $122 \mathrm{~J} / \mathrm{day}$ fins without fins $25 \mathrm{~J} /$ day to obtain fin effectiveness of $97 \mathrm{~J} /$ day. This is very influential on the production of 
condensate that is inside the condenser tube, because it can reduce the energy inside the condenser to accelerate the rate of condensation.
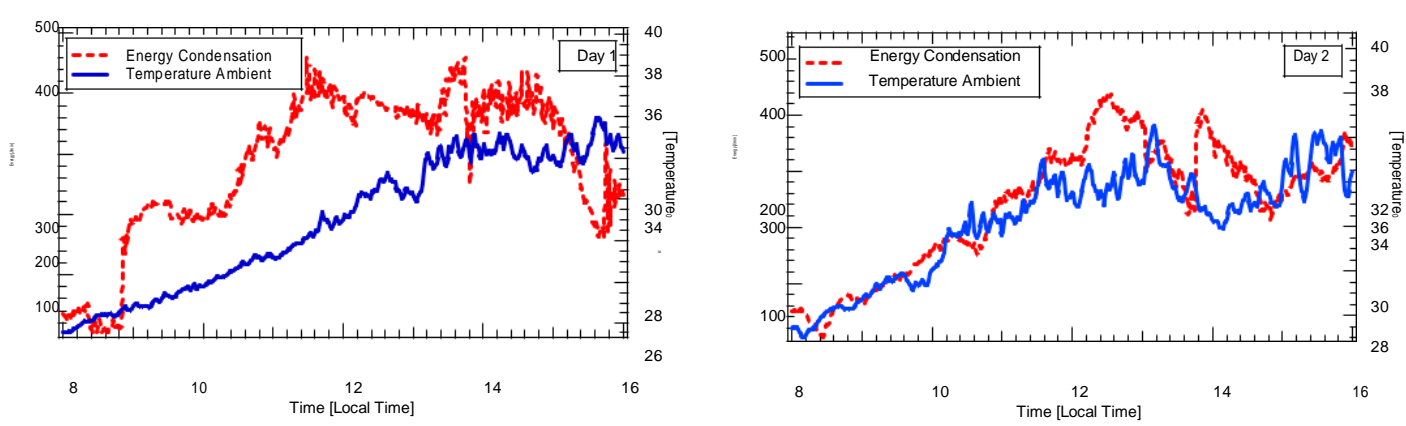

Figure 7. Energy Condensation Process

Condensation itself in this desalination system is a change of gas form into a liquid form because of the difference in temperature in the condenser, by lowering the temperature. So that condensate is formed on the condenser tube, then all condensate will go down into fresh water container. The equation below is used to find the working energy in the condenser to convert the vapor to condensate:

$$
\mathrm{Q}=\mathrm{hA}(\mathrm{Tsat}-\mathrm{Ts})
$$

Which Q is the energy, J, h the convection heat transfer coefficient, W/ m2.K, As Surface area, m2,Tsat is the water saturation temperature, ${ }^{\circ} \mathrm{C}$, the pipe surface temperature, ${ }^{\circ} \mathrm{C}$.

Energy consumption during the test from 08.00-16.00 WIB is shown in graphic form as shown in figure 7, in the experiment of the first day, the total energy is $141 \mathrm{~J} /$ day and on the second day the total energy used is $122 \mathrm{~J} /$ day, the energy use on the 1 st day is $293 \mathrm{~J} / \mathrm{min}$ while on the second day is $255 \mathrm{~J} / \mathrm{min}$.

\section{CONCLUSION}

Based on experimental results on this research, condensate rate on the 1 st day is highest at $0.00018 \mathrm{Kg} / \mathrm{min}$, with a oneday experiment average of $0.0001 \mathrm{Kg} / \mathrm{min}$, resulting in 0.8 Liter fresh water. On the $2^{\text {nd }}$ day the highest condensate rate of $0.00019 \mathrm{Kg} / \mathrm{min}$ with an average rate of condensate for one day $0.00011 \mathrm{Kg} / \mathrm{min}$, yielding fresh water of 0.81 Liter. With an average air velocity of $0.8 \mathrm{~m} / \mathrm{s}$ on day 1 while on day 2 has a speed of $0.4 \mathrm{~m} / \mathrm{s}$ helps lower the temperature on the condenser system with convection heat transfer. Evidenced by the average working temperature of condenser on day1 that is $360 \mathrm{C}$ on day- 2 the average working temperature $37.30 \mathrm{C}$. there is little difference in working temperature due to the state of the sky tidah bright because it is blocked by clouds or the weather is overcast.

\section{ACKNOWLEDGMENT}

The authors would like to thank to Eko Yohanes Setyawan, Ridho Erlanda Siregar, Agistya Dewi, Dodi Suhendra, Faisal Afif, Fattih Diwa Handalanatas for data collection in this research.

\section{REFERENCES}

[1] M.A. Eltawil, Z. Zhengming, L. Yuan, A review of renewable technologies integrated with desalination systems, Renewable Sustainable Energy Reviews, 13 (2009) 2245-2262.

[2] M. Morad, H.A El-Maghawry, K.I. Wasfy, A developed solar-powered desalination system for enhancing fresh water productivity Solar Energy Engineering, 146 (2017) 20-29.

[3] S. Al-Kharabsheh and D.Y.Goswami, Analysis of an innovative water desalination system using low-at. Desalination, 156 (2003) $323-332$.

[4] S.Al-Kharabsheh, A. and Goswami, D. Y., Theoretical analysis of a water desalinationsystem using low grade solar heat, Journal of Solar EnergyEngineering, 126 (2004)774-780.

[5] V.G.Gude, N. Nirmalakhadan, S. Deng, A. Maganti, Feasibility study of a new two-stage low temperature desalination process, Energy Conversion and Management, 56(2012)192-198.

[6] V.G. Gude and N. Nirmalakandan, Combined desalination and solar-assisted air-conditioning system, Energy Conversion and Management, (2008)3326-3330.

[7] S.C. Maroo, D.Y Goswami, Theoretical analysis of a single-stage and two-stage solar driven flash desalination system based on passive vacuum generation, Desalination, 249 (2009) 635-646.

[8] T. Ayhan, H.Al-Madani, Feasibility study of renewable energy powered seawater desalination technology using natural vacuum technique, Renewable Energy, 35 (2010) 506-514.

[9] H. Ambarita, Study on the performance of natural vacuum desalination system using low grade heat source, Case Studies in Thermal Engineering, 8 (2016) 346-358. 


\section{H. Ambarita ${ }^{1}$, E.Y. Setyawan ${ }^{2}$}

[10] H. Ambarita, Numerical study on natural vacuum solar desalination system with varying heat source temperature, IOP Conf. Series: Materials Science and Engineering 180, (2017) 012024.

[11] E.Y. Setyawan, R.A.M. Napitupulu, P. Siagian,HAmbarita, Field tests of a natural vacuum solar desalination system using hybrid solar collector, IOP Conf. Series: Materials Science and Engineering 237, (2017) 012012.

[12] Yunus, A. Cengel. Heat Transfer A Practical Approach, Second Edition. MC Graw-Hill, Book Company, 2002.

[13] S.A.Kalogirou, Seawater desalination using renewable energy sources, Progress in Energy and Combustion Science, 31 (2005)242 - 281. 